\title{
NOTAS PARA UN ANÁLISIS \\ SILOGÍSTICO DEL DISCURSO \\ JUDICIAL ${ }^{*}$
}

\section{Introducción}

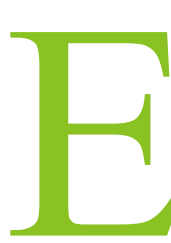

ste trabajo tiene como punto de partida dos tesis que, en relación al razonamiento judicial, han sido formuladas por Carlos Alchourrón y Eugenio Bulygin en algunos ensayos escritos entre 1989 y $1991^{1}$.

La primera tesis sostiene que el razonamiento mediante el cual los jueces motivan («justifican») sus decisiones, puede reconstruirse como un razonamiento silogístico:

«El razonamiento jurídico que pretende mostrar que una decisión o una pretensión están justificadas de acuerdo al derecho vigente es esencialmente deductivo o, por lo menos, puede ser reconstruido como una inferencia lógica en la que, sobre la base de dos tipos de premisas, normativas y fácticas, se llega a una conclusión que afirma que ciertas consecuencias jurídicas son aplicables a un caso particular» ${ }^{2}$.

La segunda tesis sostiene que los únicos «enunciados interpretativos» (asserti interpretativi, interpretative statements) utilizados por los jueces para justificar sus decisiones son enunciados analíticos:

* Deseo expresar mi gratitud a los participantes del II Seminario amero-ibero-italiano, llevado a cabo en la Residencia La Cristalera, los días 28-30 de octubre de 1996, por sus observaciones a una versión previa de este trabajo. Un agradecimiento especial merece el prof. Ricardo Caracciolo, sin cuyos comentarios, formulados en ocasión de una breve estancia genovesa, este trabajo sería sin duda peor (de lo que ya es).

${ }^{1}$ C.E. Alchourrón y E. Bulygin, «Limits of Logic and Legal Reasoning» (1989), in A. Martino (ed.), Expert Systems in Law, Amsterdam/London/New York/Tokyo, North-Holland, 1992, pp. 9-26, tr. cast., «Los límites de la lógica y el razonamiento jurídico», in C.E. Alchourrón y E. Bulygin, Análisis lógico y derecho, Madrid, C.E.C., 1991, pp. 303-328; E. Bulygin, «On legal Interpretation» (199 1), Archiv für Rechts-und Sozialphilosophie, Beiheft 53, 1994, pp. 11-22; E. Bulygin, «Cognition and Interpretation in Law» (1991), in L. Gianformaggio y S. L. Paulson (eds.), Cognition and Interpretation of Law, Torino, Giappichelli, 1995, pp. 11-35.

${ }^{2}$ C.E. Alchourrón y E. Bulygin, «Los límites de la lógica y el razonamiento jurídico», cit., p.303. 
"If the judge stipulates that the extension of the predicate $\mathrm{P}[\ldots]$ is included in the extension of the predicate $\mathrm{Q}[\ldots]$, then the statement of the language of the form (x) $(\mathrm{Px} \div \mathrm{Qx})[\ldots]$ is analytic, for its truth depends on the meaning of these predicates and not on (empirical) facts. This analytic statement that the judge uses in order to justify his rejection of [a] claim may conveniently be called interpretative statement. Such interpretative statements are based on metalinguistic rules of designation. The judge either discovers an existent semantie rule or it is he who stipulates it. In both cases he uses a true but vacuous sentence of the language; it is analytically true, but vacuous in the sonse that it does not say anything about the world. The decision of the judge to stipulate a certain semantie rule is often based on evaluations, but the interpretative sentence he uses for the justification of his veredict is not a value judgment, but an analytie statement whose truth depends on the meaning of the relevant terms alone» ${ }^{3}$.

En relación a la primera tesis, me propongo confirmarla de manera experimental (in corpore vili, tal como se verá), mostrando de qué manera el contenido de una sentencia -al menos, las sentencias pronunciadas por los jueces civiles italianos- puede ser reconstruido mediante una serie de silogismos. En efecto, un único silogismo, contrariamente a lo que sostienen ciertas teorías de la aplicación del derecho, no es normalmente suficiente para reproducir la complejidad del razonamiento justificatorio judicial.

En relación a la segunda tesis, me propongo argumentar: a) que, desde la perspectiva de una reconstrucción silogística del contenido de las sentencias lo más completa posible, los jueces, al justificar sus decisiones, utilizan no sólo enunciados interpretativos «analíticos» que expresan «proposiciones analíticas», como sostienen Alchourrón y Bulygin, sino enunciados interpretativos de otro tipo que expresan significados interpretativos de otro tipo; b) que, desde la perspectiva de una reconstrucción silogística lo más completa posible del contenido de una sentencia, no hay duda de que los jueces usan enunciados «analíticos».

Los dos apartados siguientes estarán dedicados a tratar los enunciados interpretativos (ap. 2) y los silogismos judiciales (ap. 3), con objetivos esencialmente constructivos. Se suele pensar que la crítica es el mejor modo de honrar a un estudioso. Pero una forma distinta de homenaje consiste en utilizar las teorías como base para ulteriores investigaciones. Las notas que siguen pretenden ofrecer un tributo de este último tipo al ingenio teórico de Carlos Alchourrón y de Eugenio Bulygin.

\section{Enunciados interpretativos: una tipología empírica}

¿Qué es un enunciado interpretativo? ¿Cuántos enunciados interpretativos y de qué tipo aparecen en los discursos jurídicos (en un trabajo doctrinal, en la motivación de una sentencia, etc.)? ¿Cuál es su «forma standard»?

${ }^{3}$ E. Bulygin, «On legal Interpretation», cit., pp. 16-17; análogas consideraciones en C.E. Alchourrón y E. Bulygin, «Los límites de la lógica y el razonamiento jurídico», cit., p. 306-307. 


\subsection{Definiciones y tesis}

Para evitar posibles equívocos, ilustraré brevemente las tesis y nociones de las que me he servido al elaborar la presente tipología.

1) «Enunciado». Un «enunciado» es una expresión lingüística gramaticalmente completa. Un mismo enunciado puede ser considerado en abstracto, es decir, haciendo abstracción de sus particulares y concretas utilizaciones, en cuyo caso es un «enunciado-tipo» 0 «enunciado-en-abstracto» («type-sentence»); o tomarlo en consideración tal como es utilizado en un particular contexto comunicativo, en cuyo caso es un «enunciado-en-uso» o «enunciación» («token-sentence»). En lo que sigue me ocuparé tan sólo de los enunciados-en-uso.

2) «Significado» de un enunciado. Por «significado» de un enunciado se pueden entender al menos dos cosas distintas. Por un lado, el significado (aunque podría ser perfectamente más de uno) de un enunciado en cuanto enunciado-tipo, o «significado enunciativo», o «significado acontextual»: el significado que el enunciado expresa sobre la única base de las palabras que en él aparecen y de la sintaxis. Por otro lado, el significado del enunciado en cuanto enunciado-en-uso, o «significado contextual»: la comunicación que el enunciado expresa, realiza o transmite en un particular contexto lingüístico y extralingüístico de uso, según la perspectiva de los intérpretes (destinatarios, usuarios, etc.) del propio enunciado. Asumo, al respecto, que el significado contextual (todo significado contextual) es escindible, con fines analíticos, en dos dimensiones o elementos: el elemento «referencial» y el elemento «pragmático». El elemento referencial consiste en la referencia a cosas o situaciones; el elemento pragmático refleja lo que el enunciado es -o hace, o sirve para hacer- dentro del discurso del emisor, según la perspectiva del intérprete.

3) Variedad de significados contextuales. Asumo que un mismo enunciado-tipo, según el uso particular, puede expresar (o mejor: puede entenderse que expresa) alternativamente una pluralidad de significados contextuales distintos: aserciones, constataciones, previsiones, juicios de valor, contenidos de decisiones, reglas de conducta, sugerencias, etc.

4) «Enunciadosjurídicos» / «Enunciados normativos» / «Documentos normativos».Por «enunciados jurídicos» entiendo, genéricamente, los enunciados formulados por los juristas en las obras doctrinales, por los teóricos del derecho en sus ensayos teórico-generales, por los abogados en los actos procesales, por los jueces en las sentencias, por los legisladores en las leyes, por los agentes privados en contratos y testamentos, etc. Por «enunciados normativos» (o brevemente: «disposiciones») entiendo la subclase de los enunciados jurídicos que, en un contexto espacio-temporal determinado, 
han sido formulados por autoridades normativas: por órganos competentes para producir normas, o reglas, jurídicas. Por «documento normativo» entiendo, por último, cualquier documento que contenga al menos un enunciado normativo: al menos una disposición.

5) Factores relevantes a la hora de atribuir significado a los enunciados normativos. Asumo que en la atribución de significado a los enunciados normativos pueden influir al menos cuatro factores.

El primer factor son las cogniciones, orientaciones teóricas, ideologías, exigencias prácticas y preferencias irracionales (sentimientos, pasiones, emociones) que, combinadas de manera distinta, constituyen lo que podría denominarse, por brevedad, la «perspectiva de los intérpretes».

El segundo factor es la posición institucional de quien ha formulado el enunciado normativo objeto de interpretación: órgano que detenta la función legislativa, gobierno, primer ministro, tribunal supremo, gobernador civil, alcalde, etc.

El tercer factor es la relevancia institucional del documento normativo dentro del cual ha sido formulado el enunciado objeto de interpretación.

El cuarto factor es la presencia o ausencia, en el discurso de las fuentes del derecho en sentido formal (constitución, legislación, reglamentos, etc.), de enunciados que versan sobre la interpretación: por ejemplo, la presencia o ausencia de enunciados como el art. 3.1 del código civil español, o el art. 12.1. de las disposiciones preliminares del código civil italiano.

De estos cuatro factores, el primero ejerce, paradójicamente, una influencia preponderante: es el factor, de contenidos contingentes y sociológicamente condicionados, a través del cual los otros factores asumen a su vez alguna relevancia interpretativa. Por ejemplo: si entre los juristas y los operadores jurídicos en general se ha extendido la opinión de que la interpretación es una actividad «lógica» (y no «jurídica»), así como la ideología de que el legislador no es competente para regular la interpretación de los documentos normativos (ya que, pongamos por caso, se considera que no puede hacerlo), la presencia de enunciados legislativos que versen sobre la interpretación de la ley normalmente carecerá de influencia. En efecto, cualquier intérprete que opere en aquel contexto cultural sostendrá: o que tales disposiciones, si bien se mira, no expresan ninguna regla jurídica; o que expresan preceptos jurídicos del todo inaplicables. En cambio, este tipo de disposiciones legislativas adquieren relevancia allí donde está extendida la opinión de que la interpretación es una actividad «jurídica» (y no meramente «lógica») y en presencia de ideologías prescriptivistas del discurso legislativo, para las que todos los enunciados formulados por el legislador deben ser considerados idóneos para expresar (directa o indirectamente) reglas jurídicas. 


\section{2. «Enunciado interpretativo»}

¿Cuántos enunciados interpretativos y de qué tipo se encuentran en los discursos jurídicos $\mathrm{y}$, en particular, en las sentencias?

1) La locución «enunciado interpretativo»-al igual que las correspondientes expresiones de otros lenguajes naturales: énoncé interprétatif, interpretative sentence, enunciato interpretativo, etc.- no pertenece al léxico cotidiano de los prácticos del derecho. Una locución de este tipo no posee, por tanto, un uso ordinario, susceptible de comprobación empírica.

2) Ello obviamente no implica que, si se pregunta a un juez, a un abogado o a un funcionario qué se entiende por «enunciado interpretativo», no estén en condiciones de ofrecer una respuesta. Combinando algunos de los significados de los dos vocablos que componen la locución (el sustantivo «enunciado» y el adjetivo «interpretativo»), cualquiera podría responder, por ejemplo, que «enunciado interpretativo» denota cualquier expresión lingüística gramaticalmente completa, cuyo significado tenga que ver con la interpretación de un documento normativo; o bien, de forma menos genérica, pero también circular, que «enunciado interpretativo» denota cualquier expresión lingüística gramaticalmente completa, que interprete un documento normativo.

3) La locución «enunciado interpretativo» pertenece, en cambio, al léxico de (algunos) estudiosos del derecho, que la utilizan sobre la base de estipulaciones expresas o tácitas acerca del uso que de esta locución hay que hacer, o es oportuno que se haga, en determinados contextos: por ejemplo, en virtud de una más clara comprensión del fenómeno interpretativo jurídico.

4) Por consiguiente, los enunciados interpretativos son expresiones lingüísticas gramaticalmente completas, cuya identificación dentro de los discursos jurídicos depende en gran medida de las opciones, teóricas o prácticas, de los estudiosos.

Dicho lo anterior, a los fines de la presente investigación, utilizaré una noción de «enunciado interpretativo» bastante amplia, para así evitar prejuzgar en favor de alguna meta preconstituida. Por tanto, en lo que sigue entenderé por «enunciado interpretativo» (en sentido amplio y genérico) cualquier expresión lingüística gramaticalmente completa que exprese una comunicación -aserción, constatación, previsión, juicio de valor regla de conducta, sugerimiento, decisión, etc.- relativa a la interpretación-actividad, o a la interpretación-producto, de enunciados normativos, o de particulares vocablos o locuciones dentro de ellos.

La definición utiliza la distinción, trazada por Giovanni Tarello, entre «interpretación -actividad»e «interpretación-producto»: entre la actividad consistente en atribuir significado a un enunciado normativo, actividad intelectual, 
in mente judicis, causidici, prudentis, etc., por una parte; y el resultado o producto de tal actividad, constituido por un enunciado del que se asume que tiene el mismo significado que el enunciado objeto de la interpretación, por otra ${ }^{4}$.

\subsection{Las formas standard de. los enunciados interpretativos y de sus significados contextuales} típicos

Las formas standard de los enunciados interpretativos -en lo que sigue, por brevedad: «formas-enunciado»-reproducen la estructura típica de los enunciados interpretativos presentes en los discursos jurídicos, sustituyendo sus contenidos concretos -referencias a artículos, códigos, normas, principios, etc.- por las variables simbolizadas por letras del alfabeto. Por ejemplo (otros ejemplos, en el ap. 2A):

«La disposición "D” significa N»

«La disposición “D” significa N1, N2 y N3»

«La disposición " $\mathrm{D}$ ” significa N1 o N2 o N3»

«La disposición " $\mathrm{D}$ ” no significa $\mathrm{N} 1$, sino N2»

«De la combinación de "D1","D2", ... "Dn" se obtiene N3»

«De la combinación de "D1" "D2", ... "Dn" se deduce N3»

«La disposición "D" debe ser interpretada de la forma F», etc. ${ }^{5}$

Observaciones.

1) Los enunciados interpretativos representados mediante las formas-enunciado no son enunciados interpretados. Tales formas, en efecto, no reproducen el significado de los enunciados interpretativos, sino que sirven para presentar los enunciados mismos de manera esquemática. Por ejemplo,

«La disposición “D” significa N»

es la forma-enunciado de enunciados, interpretativos, utilizados por operadores jurídicos particulares, en contextos particulares, como:

«La disposición "el domicilio es inviolable" (“D”) significa que nadie puede acceder a la vivienda de otro sin su consentimiento $(\mathrm{N})$ ».

Por su parte,

«La disposición " $\mathrm{D}$ ” debe ser interpretada del modo F»

es (en este caso) la forma-enunciado de enunciados interpretativos deónticos, tales como: «La disposición “el domicilio es inviolable” (“D”) debe ser interpretada extensivamente».

\footnotetext{
${ }^{4}$ G. Tarello, L'interpretazione della legge, Milano, Giuffrè, 1980, cap. II.

${ }^{5}$ Riccardo Guastini llama «forma standard» de los enunciados del discurso del intérprete a la fórmula siguiente: «"T" significa $S »$, donde «T» representa cualquier enunciado del discurso de las fuentes -por ejemplo: un enunciado legislativo- $\mathrm{y}$ «S» representa el contenido de significado de aquel enunciado (según la opinión del intérprete). Cfr. R. Guastini, Dalle fonti alle norme, Torino, Giappichelli, 1992, cap. 1.
} 
2) Las formas-enunciado de los enunciados interpretativos son ambiguas: conservan, por definición, la ambigüedad pragmática de los enunciados representados. Un enunciado del tipo «La disposición "D" significa N» -por ejemplo: «La disposición "el domicilio es inviolable" (“D”) significa que nadie puede acceder a la vivienda de otro sin su consentimiento (N)»- puede expresar, atendiendo a los contextos concretos de uso, una constatación, una valoración, una regla, etc. Pero la forma-enunciado no deja entrever nada de todo eso.

Las formas standard de los significados contextuales de los enunciados interpretativos -en lo que sigue, por brevedad: «formas-significado»- a diferencia de las formas-enunciado, reproducen la estructura típica de enunciados interpretativos interpretados. Sirven para mostrar el significado que tales enunciados expresan -o mejor: que los intérpretes asumen que expresanen contextos concretos de uso: reglas, constataciones, juicios de valor, previsiones, decisiones, etc. Por ejemplo:

«La disposición " $\mathrm{D}$ ” debe interpretarse que expresa $\mathrm{N}$ (en el contexto Q»

C)»

«La disposición "D" ha sido interpretada (por a, b, c,... n) expresando N (en el contexto

«Es justo atribuir a la disposición " $\mathrm{D}$ ” el significado N»

«Es previsible que a la disposición " $D$ ” se le atribuya el significado N»

Nótese que, desde la perspectiva de las presentes estipulaciones, cada una de las formas - significado reproduce una posible interpretación de un enunciado-en-uso interpretativo, cuya forma-enunciado sería: «La disposición " $D$ " significa N». No es raro, en efecto, que los enunciados-en-uso interpretativos sean elípticos y, en cuanto tales, aptos para generar confusión y opiniones encontradas sobre su significado contextual.

\subsection{Una tipología empírica}

Partiendo de la distinción de Tarello, entre enunciados interpretativos que expresan, respectivamente, constataciones, decisiones, previsiones y propuestas ${ }^{6} ; \mathrm{y}$ entendiendo por «enunciado interpretativo», según lo estipulado con anterioridad, toda expresión lingüística gramaticalmente completa que expresa una comunicación -aserción, constatación, previsión, juicio de valor, valoración técnica, regla de conducta, sugerimiento, decisión, etc.- relativa a la interpretación-actividad o a la interpretación-producto de disposiciones, es posible distinguir, dentro de los discursos jurídicos, diversos tipos de enunciados interpretativos. A continuación examinaré sólo algunos de ellos. Con una precisión. La siguiente tipología es «empírica» en al menos

\footnotetext{
${ }^{6} \mathrm{G}$. Tarello, L'interpretazione della legge, cit., cap. II.
} 
tres sentidos distintos. En primer lugar, se fundamenta en constataciones o en generalizaciones de constataciones, de datos de la experiencia. En segundo lugar, pretende ser un instrumento analítico de los discursos interpretativos en experiencias jurídicas particulares. En tercer lugar, es el resultado de un enfoque «empírico», de bajo contenido de reelaboración teórica.

(1) Enunciados que regulan interpretaciones-actividad. Un primer tipo de enunciado interpretativo está formado por aquellos enunciados que expresan reglas jurídicas acerca de qué procedimiento interpretativo debe seguirse por parte de ciertos sujetos en relación a enunciados normativos individuales o a clases de enunciados normativos. Por ejemplo, «Al aplicar la ley no se le puede atribuir otro sentido que el que surge del significado propio de las palabras»; «Las leyes de excepción deben interpretarse de manera restrictiva»; «Si hay dudas, los contratos a título oneroso deben ser interpretados dando un tratamiento equitativo a la exigencia de las partes»; «La disposición "Los ciudadanos tienen derecho a reunirse pacíficamente y sin armas" debe ser interpretada según el principio de favor libertatis», etc.

La forma-significado de enunciados regulativos que versan sobre clases de enunciados normativos, o de enunciados individuales en cuanto pertenecen a tales clases (artículos, cláusulas contractuales, codicilos, etc.), es:

«Toda D debe interpretarse de la forma F (en C)».

Por su parte, la forma-significado de enunciados regulativos que versan sobre enunciados normativos individuales (o acerca de locuciones dentro de enunciados: en lo que sigue no repetiré esta precisión, dándola por implícita) es:

«La disposición " $\mathrm{D}$ ” debe interpretarse de la forma $\mathrm{F}$ (en $\mathrm{C}$ )».

Observaciones

a) En ocasiones aparecen enunciados regulativos en el lenguaje legislativo -al menos en el de aquellos legisladores que cuentan entre sus tareas con la de regular la interpretaciónactividad: este es el caso, por ejemplo, del legislador argentino, italiano y español.

b) También aparecen enunciados regulativos en el discurso judicial, cuando se trata de jueces competentes para producir reglas generales que otros sujetos -los mismos jueces o jueces inferiores en decisiones sucesivas, funcionarios, ciudadanos- deben seguir.

c) En ocasiones, los juristas en sus discursos formulan enunciados deónticos del tipo: «La ley penal debe ser interpretada de forma extensiva»; o "La disposición "Todos los ciudadanos son iguales ante la ley" debe ser interpretada de forma restrictiva». Sin embargo, discursos doctrinales cuya forma-enunciado sea, por ejemplo, «La disposición " $\mathrm{D}$ " debe interpretarse de la forma $\mathrm{F}$ (en $\mathrm{C}$ )» son ambiguos: no expresan necesariamente reglas interpretativas, sino que, según las características de la experiencia jurídica en 
la que el enunciado ha sido formulado y según la perspectiva de quien lo interpreta (cfr. ap. 2.1.), pueden entenderse, por ejemplo, como enunciados que expresan valoraciones prudenciales («enunciados estimativos»), juicios de valor («enunciados valorativos»), previsiones («enunciados predictivos»), propuestas («enunciados propositivos»), constataciones («enunciados constatativos»), etc. Por ejemplo, un enunciado interpretativo cuya forma-enunciado sea:

«La disposición " $\mathrm{D}$ ” debe interpretarse de la forma $\mathrm{F}$ (en C)»,

si lo ha formulado un jurista que opera en un ordenamiento moderno del tipo europeo-continental, podría expresar (entenderse que expresa) elípticamente una constatación, según la cual, en cierto contexto (C), es vigente la regla de que se debe interpretar cierta disposición ("D") según cierto procedimiento (F). En tal caso, la forma-significado sería:

«En $\mathrm{C}$, es vigente la regla según la cual la disposición “ $\mathrm{D}$ ” debe ser interpretada de la forma $F »$.

O bien, un enunciado doctrinal de este tipo podría también (entenderse que) expresa una propuesta regulativa de lege lata: la propuesta de adoptar una cierta regla interpretativa, formulada por el jurista mediante un enunciado deóntico (por dárselas de nomoteta, o por intentar suscitar en los destinatarios una postura similar a la que adoptarían frente a un idéntico mensaje proviniente, pongamos por caso, del legislador), en cuyo caso la forma-significado del enunciado sería:

«Se propone, al interpretar la disposición "D", que se adopte la regla según la cual "D" debe interpretarse de la forma $\mathrm{F}$ (en $\mathrm{C}$ )».

d) ¿Cómo entender los enunciados interpretativos deónticos -«La ley debe interpretarse según el sentido propio de las palabras», «El art. 1593 del Código Civil debe interpretarse de forma sistemática», etc.- usados en una sentencia por un juez que no tenga la competencia para producir reglas jurídicas vinculantes erga omnes? La respuesta requiere ulteriores precisiones y depende, en buena medida, de la perspectiva teórica adoptada ${ }^{7}$.

$\mathrm{Al}$ respecto, sin embargo, cabe sostener que este tipo de enunciados expresan, según los casos, al menos tres distintas proposiciones interpretativas (uso «proposición», genéricamente, como sinónimo de significado de un enunciado y no como significado verdadero o falso).

En algunos casos, un enunciado judicial cuya forma-enunciado es:

«La disposición " $\mathrm{D}$ ” debe ser interpretada de la forma $\mathrm{F}$ (en C)»

podría expresar (o entenderse que expresa) un «precepto derivado» del tipo «meramente reiterado», o sea, estipulativamente, un precepto: a) no

\footnotetext{
${ }^{7}$ Sobre este punto, E. Bulygin, «Sentencia judicial y creación de derecho» (1966), in C. E. Alchourrón y E. Bulygin, Análisis lógico y derecho, cit., pp. 355-369.
} 
producido originaria y libremente por el juez, sino obtenido de una preexistente disposición; b) que constituye la pura y simple reiteración del texto de la disposición (o la simple paráfrasis de su significado más inmediato). En tales situaciones, la forma-significado del enunciado interpretativo es la siguiente:

«Conforme a lo prescrito por D1, la disposición ' $\mathrm{D}$ ' debe interpretarse de la forma $\mathrm{F}$ (en C)».

En otros casos, un enunciado judicial cuya forma-enunciado es:

«La disposición " $\mathrm{D}$ ” debe ser interpretada de la forma $\mathrm{F}$ (en $\mathrm{C}$ )»

podría expresar (o entenderse que expresa) un «precepto derivado» del tipo «no meramente reiterativo», es decir, estipulativamente, un precepto: a) no producido originaria y libremente por el juez, sino obtenido de una base enunciativa que puede incluir también una pluralidad de disposiciones recortadas y combinadas de forma variada; b) que constituye el resultado de operaciones interpretativas más o menos complejas: desde la «concreción» de cláusulas generales hasta la identificación de principios generales implícitos en el discurso de las fuentes, y si se da el caso, con el auxilio de precedentes interpretaciones-producto con autoridad, sea de origen doctrinal o judicial. En tales situaciones, la forma-significado del enunciado interpretativo es la siguiente:

«Conforme a lo prescrito por la base enunciativa relevante BE (vistos los criterios hermenéuticos R1 ... Rn y de las técnicas hermenéuticas $\mathrm{T} 1 \ldots \mathrm{Tn}$ ), la disposición " $\mathrm{D}$ ” debe interpretarse de la forma $\mathrm{F}$ (en C)».

En ocasiones, en relación a este último tipo de preceptos derivados, se suele hablar de «normas producidas por los jueces». No obstante, la principal (e inmediata) función de tales «normas», al menos por lo que hace a las organizaciones de tipo europeo-continental, no es la de guiar el comportamiento de clases de destinatarios indeterminados (en los que, normalmente, subsiste un deber jurídico de obediencia), sino hacer las veces de rationes decidendi (o de regulae decidendi) para un caso determinado. Tales rationes decidendi pueden también aplicarse de nuevo en sucesivas decisiones: su «vigencia» respecto a clases de destinatarios indeterminados sigue siendo, a pesar de todo, una vigencia meramente factual; y la observancia de las mismas, por parte de los asociados, se debe a consideraciones esencialmente prudenciales y no a consideraciones lato sensu morales.

\footnotetext{
${ }^{8}$ De «preceptos reiterados» habla Uberto Scarpelli, «Le "proposizioni giuridiche" come precetti reiterati», Rivista internazionale di filosofia del diritto, 44, 1967, pp. 465-482, para denominar en general lo que en el texto he llamado «preceptos derivados». Además de lo dicho por Scarpelli, estas breves consideraciones son deudoras, bajo el perfil de las relaciones entre regula decidendi y discurso de las fuentes, de J. Wróblewski, The Judicial Application of Law, Dordrech/Boston/London, Kluwer, 1992, pp. 242-250, el cual utiliza la expresión «rule of decision».
} 
Por último, en otros casos, un enunciado judicial cuya forma-enunciado sea:

«La disposición " $\mathrm{D}$ ” debe interpretarse de la forma $\mathrm{F}$ (in $\mathrm{C}$ )»

podría expresar un precepto derivado -meramente reiterado o no- pero, por ejemplo, una valoración prudencial (un juicio estimativo), de tal modo que su forma-significado no sería:

«La disposición “ $\mathrm{D}$ ” debe interpretarse de la forma $\mathrm{F}$ (in $\mathrm{C}$ )», sino:

«Es correcto interpretar la disposición " $\mathrm{D}$ ” de la forma $\mathrm{F}$ (en $\mathrm{C}$ )».

(2) Enunciados que regulan interpretaciones-producto. Un segundo tipo de enunciado interpretativo está formado por aquellos enunciados que expresan reglas acerca de qué significado debe atribuirse a enunciados normativos específicamente delimitados. Por ejemplo, «La disposición "La correspondencia es inviolable" debe interpretarse que expresa la norma según la cual las comunicaciones epistolares (pero no las telefónicas) quedan sustraídas al control preventivo de la policía».

La forma-significado de este tipo de enunciados es:

«La disposición "D” debe interpretarse que expresa N (en C)».

Observaciones.

a) Con notable frecuencia aparecen enunciados regulativos de interpretaciones-producto en el discurso legislativo. Se trata de los enunciados que expresan las llamadas «normas interpretativas»o «normas de interpretación auténtica» de otros enunciados normativos.

b) En presencia de determinadas condiciones estructurales, aparecen este tipo de enunciados regulativos también en el discurso judicial. En Italia, por ejemplo, la Corte de casación, cuando anula una sentencia pronunciada en apelación o en única instancia por «violación o falsa aplicación de normas jurídicas», debe formular el «principio de derecho» con el que el juez de reenvío deberá decidir el fondo de la controversia. Pues bien, en muchos casos, la casación dirige al juez de reenvío reglas del tipo: «La disposición " $\mathrm{D}$ ” debe interpretarse que expresa $\mathrm{N}($ en $\mathrm{C}) »$.

c) En relación a los discursos de los juristas y de los jueces no competentes para formular reglas vinculantes erga onmes, valen aquí las mismas consideraciones desarrolladas en relación a los enunciados regulativos de interpretaciones-actividad.

(3) Enunciados valorativos de interpretaciones y actividad. Un tercer tipo de enunciado interpretativo está formado por los enunciados que expresan juicios de valor-morales, políticos, religiosos, etc.- acerca de la interpretación-actividad de enunciados normativos individuales o de clases de enunciados normativos. Por ejemplo, «Es bueno que las leyes de excepción sean interpretadas restrictivamente»; «Hay que abstenerse de interpretar extensivamente 
las leyes penales»; «Es justo que la disposición "Los ciudadanos tienen derecho a reunirse pacíficamente y sin armas" se interprete según el principio de favor libertatis», etc.

La forma-significado de este tipo de enunciados que versan sobre clases de enunciados normativos es:

«Es justo que toda D se interprete de la forma $\mathrm{F}$ (en C)».

Por su parte, la forma-significado de este tipo de enunciados que versan sobre enunciados normativos individuales es:

«Es justo que la disposición “ $\mathrm{D}$ ” se interprete de la forma $\mathrm{F}$ (en $\mathrm{C}$ )».

Observaciones.

a) Usualmente, los enunciados valorativos no aparecen en el discurso legislativo -al menos no lo hacen en la cultura continental moderna, al asumirse que el legislador debe únicamente prescribir: no debe ni persuadir, ni informar, ni expresar juicios de valor.

b) En cambio, aparecen enunciados valorativos típicamente en los discursos de los juristas y, en cierta medida, en el de los jueces, en cuanto estos últimos, en un determinado contexto cultural-organizativo, consideren que pueden formular verdaderos y propios juicios de valor en las sentencias, sin que ello suscite reacciones críticas por parte de la opinión pública ni censuras por parte de los garantes de la deontología judicial.

(4) Enunciados valorativos de interpretaciones-producto. Un cuarto tipo de enunciado interpretativo está formado por los enunciados que expresan juicios de valor-morales, políticos, religiosos, etc- acerca de la interpretación-producto de enunciados normativos específicamente determinados. Por ejemplo: «Existe el deber inexcusable de entender por "sociedad de auxilio mutuo" toda forma de agregación humana inspirada en los principios del panglosianismo culinario»».

La forma-significado de este tipo de enunciados es:

«Es justo que "D" se interprete que expresa $\mathrm{N}$ en $\mathrm{C}$ ».

Observaciones.

a) Este tipo de enunciados normalmente tampoco aparecen -o se espera que no aparezcanen el discurso legislativo.

b) En cambio, están presentes, si bien a menudo de manera disimulada, en los discursos de los juristas.

c) Pueden estar presentes, bajo determinadas circunstancias culturales-organizativas, en los discursos de los jueces.

(5) Enunciados estimativos de interpretaciones-actividad. Un quinto tipo de enunciado interpretativo está formado por aquellos enunciados que expresan valoraciones técnicas o prudenciales, sobre la interpretación-actividad de enunciados normativos individuales o de clases de enunciados normativos. Por ejemplo: «Es oportuno interpretar las leyes penales de forma 
extensiva (si se quiere contrarrestar eficazmente la criminalidad)»; «Conviene interpretar los contratos literalmente (si se quiere evitar sustituir la voluntad de las partes por la del juez)»; «Es oportuno interpretar el art. 1 de la ley sobre vacaciones perpetuas de forma restrictiva (si se quiere dar una lectura conforme a los principios del derecho, o a la eficiencia)», etc.

La forma-significado de este tipo de enunciados que versan sobre clases de enunciados normativos es:

«Es oportuno que toda $\mathrm{D}$ se interprete de la forma $\mathrm{F}$ (dado el objetivo $\mathrm{T}$ )».

Por su parte, la forma-significado de este tipo de enunciados que versan sobre enunciados normativos individuales es:

«Es oportuno que "D” se interprete de la forma F (dado el objetivo T)».

Observaciones.

a) En cuanto a la presencia de este tipo de enunciados en los discursos jurídicos, valen las mismas consideraciones que respecto a los enunciados que expresan juicios de valor relativos a interpretaciones-actividad. Con una precisión. Las valoraciones estimativas representan -de maneras normalmente más complejas que las que aquí se han ejemplificado- el producto típico de una doctrina jurídica tecnológica de jure conditio y de sentencia ferenda: de una doctrina interesada en dirigir a los jueces propuestas operativas, en función de los fines predeterminados que se asume hay que perseguir.

b) Las valoraciones prudenciales, por tanto, son susceptibles de un control de racionalidad instrumental: basado en la subsistencia o no de un nexo de medio a fin entre la solución interpretativa propuesta como oportuna, por un lado, y el fin o valor en función del cual aquélla sería oportuna, por otro. Como es obvio, este tipo de control no prejuzga la justificación de la elección de ciertos fines, o de ciertos valores, como objetivos que merezcan ser perseguidos.

c) Las valoraciones estimativas representan un tipo de juicio que los jueces -en cuanto intérpretes y aplicadores de un derecho (que se asume) en gran parte preconstituido (al menos bajo la forma de enunciados del discurso de las fuentes)- formulan usualmente para justificar sus decisiones interpretativas.

(6) Enunciados estimativos de interpretaciones-producto. Un sexto tipo de enunciado interpretativo está formado por aquellos enunciados que expresan valoraciones técnicas, o prudenciales, sobre la interpretación-producto de enunciados normativos específicamente individualizados. Por ejemplo, «(Si se quiere contrarrestar eficazmente la criminalidad) se debe interpretar la disposición "Los condenados a reclusión pueden disfrutar de la libertad condicional" en el sentido de que sólo los condenados no peligrosos socialmente pueden beneficiarse de la libertad condicional». 
La forma-significado de este tipo de enunciados es:

«Es oportuno que " $\mathrm{D}$ ” se interprete que expresa $\mathrm{N}$ (dado el objetivo T)».

En cuanto a la presencia de este tipo de enunciado valen las consideraciones hechas acerca de los enunciados estimativos de interpretaciones-actividad.

(7) Enunciados que expresan previsiones relativas a interpretaciones-actividad. Un séptimo tipo de enunciado interpretativo está formado por aquellos enunciados que expresan previsiones, por parte de los emisores, acerca de la interpretación-actividad de enunciados normativos individuales o de clases de enunciados normativos, por parte de determinados intérpretes. Por ejemplo: «Las organizaciones patronales interpretarán la ley de las vacaciones perpetuas de forma restrictiva»; «Es probable que los jueces interpreten las disposiciones tributarias en base al principio del favor Aerarii», «Muy probablemente, la locución "gato de lujo" será interpretada de forma extensiva (por el administrador de finanzas)», etc.

La forma-significado de este tipo de enunciados que versan sobre clases de enunciados normativos es:

«Es previsible que toda $\mathrm{D}$ sea interpretada de la forma $\mathrm{F}$ (en $\mathrm{C}$ )».

Por su parte, la forma-significado de este tipo de enunciados que versan sobre enunciados normativos es:

«Es previsible que la disposición " $\mathrm{D}$ " sea interpretada de la forma $\mathrm{F}$ (en C)».

Observaciones.

a) Los enunciados predictivos -las presentes consideraciones valen también para los enunciados predictivos relativos a interpretaciones-producto, que veremos a continuaciónaparecen típicamente en los discursos de los juristas y los abogados.

b) Son normalmente extraños -al menos en la cultura jurídica occidental- en el discurso legislativo.

c) Son normalmente extraños -al menos en la cultura jurídica occidental- en el discurso judicial. Con las precisiones siguientes. Enunciados prima facie predictivos -reproducibles mediante formas-enunciado predictivas- pueden aparecer en las sentencias. Sin embargo, cabe la duda de que sean entendidos (por los intérpretes) como enunciados efectivamente predictivos. Si un tribunal supremo afirma: «Siempre que un caso análogo al presente se presente dentro de un año a la consideración de este tribunal, la disposición " $\mathrm{D}$ ” será interpretada de la forma $\mathrm{F}$ ”, la forma-significado correspondiente no será, probablemente:

«(Siempre que un caso análogo al presente se presente dentro de un año a la consideración de este tribunal) Es previsible que la disposición " $\mathrm{D}$ " sea interpretada de la forma $\mathrm{F}(\mathrm{en} \mathrm{C} 1) »$, 
sino, por ejemplo:

«(Siempre que un caso análogo al presente se presente dentro de un año a la consideración de este tribunal) Se decide que la disposición " $\mathrm{D}$ " sea interpretada de la forma $\mathrm{F}$ (en $\mathrm{C} 1) »$.

(8) Enunciados que expresan previsiones relativas a interpretaciones-producto. Un octavo tipo de enunciado interpretativo está formado por aquellos enunciados que expresan previsiones, por parte de los emisores, acerca de la interpretación-producto de enunciados normativos específicamente individualizados, por parte de determinados intérpretes. Por ejemplo, «Muy probablemente, las organizaciones patronales entenderán por "vacaciones perpetuas", las vacaciones que se disfrutan en conexión a la irreversible cesación de las funciones cerebrales del prestador de trabajo»; «La locución “gato de lujo" será interpretada (por el administrador de finanzas) como todo felino doméstico inapetente», etc.

La forma-significado de este tipo de enunciados es:

«Es previsible que "D" sea interpretada expresando N (en C)».

(9) Enunciados que expresan constataciones relativas a interpretaciones-actividad. Un noveno tipo de enunciado interpretativo está formado por aquellos enunciados que expresan constataciones, por parte de los emisores, de la interpretación-actividad de enunciados normativos individuales, o clases de enunciados normativos, por parte de determinados intérpretes. Por ejemplo, «La mayoría de los iusprivatistas interpreta las disposiciones sobre la interrupción de la prescripción de manera restrictiva»; «Los jueces se apartan del significado literal de las palabras, siempre que aquél les conduzca a consecuencias absurdas»; «En Rongovia, no hay jurista que atribuya peso alguno a la intención del legislador», etc.

La forma-significado de este tipo de enunciados que versan sobre clases de enunciados normativos es:

«Se puede constatar (se constata, es constatable, etc.) que toda D ha sido interpretada de la forma $\mathrm{F}$ (en C)».

Por su parte, la forma-significado de este tipo de enunciados que versan sobre enunciados normativos individuales es:

«Se puede constatar (se constata, es constatable, etc.) que " $D$ " ha sido interpretada de la forma $\mathrm{F}$ (en $\mathrm{C})$ ».

Observaciones.

a) Las constataciones de interpretaciones-actividad -al igual que las relativas a las interpretaciones-producto- no pertenecen, usualmente, al discurso legislativo.

b) En cambio, son un componente esencial de los discursos de jure conditio -o de lege lata- de los juristas. 
c) Aparecen en el discurso judicial únicamente en presencia de circunstancias culturales y organizativas totalmente contingentes. Por ejemplo, la Corte de casación italiana, al motivar, formula a menudo constataciones interpretativas; en cambio, la Corte de casación francesa, que motiva según la técnica de la "phrase-unique», las evita totalmente.

(10) Enunciados que expresan constataciones relativas a interpretaciones-producto. Un décimo tipo de enunciado interpretativo está formado por aquellos enunciados que expresan la constatación, por parte del emisor, de la interpretación-producto de enunciados normativos específicamente individualizados, por parte de determinados intérpretes. Por ejemplo, «Para el Tribunal secreto del imperio, hasta 1989, «buena fe» era sinónimo de cándida ingenuidad bucólica».

La forma-significado de este tipo de enunciados es:

«Se puede constatar ( se constata, es constatable, etc.) que "D” ha sido interpretada expresando $\mathrm{N}$ (en C)».

Los dos tipos de enunciados constatativos, o asertivos, que se acaban de mencionar deben ser distinguidos de aquellos enunciados constatativos que versan no ya sobre hábitos o comportamientos interpretativos (más o menos extendidos), sino sobre otros enunciados interpretativos (prescriptivos, valorativos, estimativos, predictivos, etc.).

(11) Enunciados que expresan propuestas relativas a interpretaciones-actividad. Un undécimo tipo de enunciado interpretativo está formado por los enunciados que expresan la propuesta, o la sugerencia, por parte del emisor, de interpretar un cierto enunciado normativo, o una cierta clase de enunciados normativos, utilizando un determinado procedimiento hermenéutico. Por ejemplo: «Sería bueno interpretar las leyes penales de forma extensiva»; «Se debe interpretar "ciudadanos" a la luz de los principios del comunitarismo tribal», etc.

La forma-significado de este tipo de enunciados que versan sobre clases de enunciados normativos es:

«Se propone interpretar toda D de la forma $\mathrm{F}$ (en C)».

Por su parte, la forma-significado de este tipo de enunciados que versan sobre enunciados normativos individuales es, por ejemplo:

«Se propone interpretar "D" de la forma F (en C)».

(12) Enunciados que expresan propuestas relativas a interpretaciones-producto. Un duodécimo tipo de enunciado interpretativo está formado por los enunciados que expresan la propuesta, o la sugerencia, por parte del emisor, de atribuir a un enunciado normativo, o a un vocablo o locución internos, un cierto significado. Por ejemplo: «Sería bueno interpretar "ciudadano" como todo aquel individuo residente, con sólida fe zoroastriana».

La forma-significado de este tipo de enunciados es: 
«Se propone interpretar “D” expresando N (en C)».

Observaciones.

a) Los enunciados que expresan propuestas -relativas tanto a interpretaciones-actividad, como a interpretaciones-producto- no aparecen, normalmente, en el discurso legislativo.

b) Aparecen típicamente, en cambio, en los discursos de los juristas, como corolario de argumentaciones en las que aquéllos formulan juicios interpretativos, valorativos o prudenciales, y asumen decisiones interpretativas. Tales discursos serían, por lo demás, del todo vanos, si no se acompañaran de la propuesta de que las soluciones adoptadas sean recogidas por los otros juristas y por los jueces.

c) Sólo en presencia de determinadas condiciones culturales y organizativas este tipo de enunciados encuentran lugar en el discurso judicial. En la cultura y organización jurídica italiana actual, por ejemplo, los enunciados interpretativos (que se consideran) típicamente formulados en la motivación de las sentencias son aquellos que expresan constataciones, juicios estimativos (de interpretaciones-actividad, de interpretaciones-producto, sobre el contenido de decisiones interpretativas, etc.), y reglas interpretativas derivadas (en el sentido dado en el n. 1), o son enunciados mediante los cuales los jueces manifiestan una decisión sobre cuestiones interpretativas promovidas por las partes.

(13) Enunciados que expresan decisiones relativas a una interpretación-actividad. Un decimotercer tipo de enunciado interpretativo está formado por aquellos enunciados mediante los cuales el emisor formula una decisión relativa a una interpretación-actividad. Por ejemplo: «Este tribunal interpreta la ley sobre las vacaciones perpetuas de modo restrictivo», «El vocablo "ciudadanos" no puede interpretarse de manera extensiva», etc.

La forma-significado de este tipo de enunciados que versan sobre clases de enunciados normativos es:

«Se decide interpretar toda D de la forma F (en C)».

Por su parte, la forma-significado de este tipo de enunciados que versan sobre enunciados normativos individuales es, por ejemplo:

«Se decide interpretar "D" de la forma F (en C)».

(14) Enunciados que expresan decisiones relativas a una interpretación-producto. Un decimocuarto tipo de enunciado interpretativo, finalmente, está formado por aquellos enunciados mediante los cuales el emisor formula una decisión relativa a una interpretación-producto de un enunciado normativo. Por ejemplo: «Este tribunal interpreta «domicilio» como todo lugar de disposición exclusiva de un sujeto privado», etc.

La forma-significado de este tipo de enunciados es:

«Se decide que " $D$ " signifique $N($ en $C) »$. 
Observaciones.

a) Los enunciados decisorios relativos a interpretaciones -producto son los únicos enunciados mediante los cuales los intérpretes, manifestando la decisión de atribuir un cierto significado a un documento jurídico, lo interpretan.

b) Tales enunciados tienen a menudo la forma-enunciado: «La disposición " $\mathrm{D}$ ” significa N».

c) Todos los demás tipos de enunciado interpretativos que hemos visto son, en cambio, enunciados mediante los cuales los intérpretes cumplen actividades distintas a la de interpretar, si bien estrechamente relacionadas con ella: se trata, en suma, de prescribir cómo se debe interpretar, de formular un precepto interpretativo derivado con fines justificatorios, de constatar cómo se ha interpretado, de sugerir cómo se puede interpretar, de prever cómo se interpretará, de justificar una interpretación-actividad o una interpretación-producto respecto a un determinado fin, de justificar una interpretación-actividad o una interpretación-producto a la vista de determinados valores morales o políticos, y así sucesivamente.

d) Como se ha dicho, el inventario es incompleto. No se han incluido, por ejemplo, los enunciados interpretativos que versan sobre reglas interpretativas: que constatan la vigencia de un determinado criterio hermenéutico relativo a interpretaciones-actividad 0 a interpretaciones-producto.

e) Por último, el inventario debería ampliarse si se adoptara una noción más extensa de «interpretación», que denotara no sólo la atribución de significado a disposiciones, sino también las operaciones que consisten en «colmar» las lagunas y en resolver las antinomias.

\subsection{Dos tipologías comparadas}

2.5. 1. Enunciados interpretativos «analíticos» y discurso judicial

Alchourrón y Bulygin, en los escritos mencionados en la introducción, distinguen tres tipos de enunciado interpretativo: los enunciados descriptivos, los enunciados estipulativos y los enunciados analíticos 9 .

Los enunciados descriptivos corresponden, aparentemente, a una subclase de los enunciados constatativos de interpretaciones-producto (ap. 2.4., n. 12), teniendo como objeto no ya el significado de enunciados normativos, sino de cada «signo descriptivo» dentro de ellos. En efecto, ¿qué significa «describir las reglas semánticas» que de hecho presiden el uso de un cierto vocablo, si no es el hecho de dar cuenta de los resultados de constataciones

\footnotetext{
${ }^{9}$ C.E. Alchourrón y E. Bulygin, «Los límites de la lógica y el razonamiento jurídico», cit., p.324.
} 
acerca del significado con el cual aquel vocablo es usado en una determinada comunidad lingüística?

Los enunciados estipulativos corresponden, aparentemente, a una subclase de los enunciados decisorios relativos a interpretaciones-producto (ap. 2A., n. 16), teniendo como objeto no ya el significado de enunciados normativos, sino de cada signo descriptivo dentro de ellos. En efecto, ¿qué significa «estipular las reglas semánticas» que de hecho presiden el uso de un cierto vocablo, si no es el hecho de decidir cuál sea su significado en relación a un determinado contexto de uso? Los enunciados analíticos, en cambio, no corresponden a ninguno de los enunciados interpretativos inventariados anteriormente. Al respecto, pueden avanzarse al menos tres diversas hipótesis. Primera hipótesis: el inventario de enunciados interpretativos del apartado 2A., por un lado, y la tipología de Alchourrón y Bulygin, por otro, pertenecen a perspectivas y a universos de discurso heterogéneos, de tal modo que las dos tipologías no son comparables entre sí (salvo las correspondencias que se acaban de mostrar). Segunda hipótesis: el inventario que he delineado presenta una grave laguna, que deberá ser llenada, y allí donde no sea posible a la vista del aparato conceptual utilizado para redactarlo, habrá que modificarlo oportunamente. Tercera hipótesis: el inventario no contiene «enunciados interpretativos» analíticos, porque parece teóricamente poco oportuno incluirlos bajo tal denominación.

Formularé a continuación algunas razones en favor de esta última hipótesis -razones posteriormente corroboradas, creo, por lo que procuraré mostrar en el párrafo siguiente.

1) Del elenco de los enunciados interpretativos, aquellos que tienen que ver con la interpretación -producto de específicas expresiones lingüísticas (enunciados, o locuciones o vocablos internos)- o sea, aquellos que, en el léxico de Alchourrón y Bulygin, tienen que ver con la «especificación» del significado de particulares signos descriptivos- son todos susceptibles de ser representa os mediante formas-significado en las que la expresión del significado que se trate está simbolizada por una variable entrecomillada («D») (ap., 2.4., nn. 2, 4, 6, 8, 10, 12, 14).

2) Los enunciados interpretativos descriptivos o estipulativos de los que hablan Alchourrón y Bulygin son igualmente susceptibles de ser representados mediante tal simbología. En particular, la constatación o la estipulación según la cual un predicado está incluido en otro predicado -que Alchourrón y Bulygin representan mediante la fórmula lógica «F $<\mathrm{G} »$ - pueden ser representadas, respectivamente, mediante las dos formas-significado siguientes: 
«Se constata que la expresión «G» ha sido interpretada denotando F (en G)», o:

«Se decide que la expresión "G" denote F (en C)».

Se trata, en efecto, de enunciados metalingüísticos, en los cuales las expresiones pertenecientes al lenguaje objeto no son usadas, sino definidas.

3) Por definición, en cambio, los enunciados interpretativos «analíticos» no pueden ser representados mediante formas-significado que contengan símbolos entrecomillados: si no es al precio de perder su carácter analítico.

Considérese el siguiente ejemplo. Dado el enunciado «interpretativo»:

«Los contratos celebrados los domingos (CCD) son contratos sacrílegos (CS)»,

su forma-enunciado es:

«Todos los CCD son CS»

y su forma lógica, como se recordará, es:

(x) (CCDx $\ddot{y}$ CSx).

No es posible, en cambio, representar tal enunciado mediante la siguiente forma-enunciado:

«La expresión «CS» denota (también) CCD»

Esta forma reproduce esquemáticamente un enunciado del siguiente tenor:

«La expresión "contrato sacrílego" (“CS”) denota (también) todo contrato celebrado en domingo (CCD)».

Un enunciado de este tipo, empero, no es un enunciado analítico: no usa la expresión «contrato sacrílego», sino que la menciona con el fin de especificar su significado.

4) Alchourrón y Bulygin, por tanto, utilizan tácitamente una noción de enunciado interpretativo que, al menos bajo un aspecto, es aún más amplia que la que se halla en la base de la presente tipología. Desde la perspectiva de los dos estudiosos, «enunciado interpretativo» denota no sólo los enunciados que tienen que ver con la atribución de significado a una expresión lingüística, sino también los enunciados que son el resultado de la aplicación de ciertas reglas semánticas, constatadas o estipuladas por los intérpretes. Los «enunciados interpretativos» analíticos, sin embargo: a) son enunciados que pueden formarse y usarse sólo después de que la actividad interpretativa, aun entendida de manera lata, haya concluido; b) por definición, no ofrecen ninguna información, prescripción, etc. sobre interpretaciones-actividad o sobre interpretaciones-producto de disposiciones; c) por el contrario, sólo después de haber recogido informaciones sobre prácticas y/o decisiones interpretativas se puede identificarlos (rectius: interpretarlos), dentro de un discurso judicial determinado, como enunciados analíticos. 
Las anteriores constituyen una serie de razones, al menos desde el punto de vista de estas notas, para no incluir enunciados analíticos de este tipo en la clase de los enunciados interpretativos, aunque se entiendan de manera lata. En efecto, aquéllos no son «interpretativos», $\mathrm{y}$, además, resultan ser heterogéneos respecto a las otras dos clases de enunciados «interpretativos» identificados por Alchourrón y Bulygin.

5) Enunciados como «Los contratos celebrados los domingos son contratos sacrílegos» presentan una fatal ambigüedad ${ }^{10}$.

Para Alchourrón y Bulygin estos enunciados expresarían, en el discurso judicial (o en todo caso en su reconstrucción lógica), proposiciones analíticas: verdaderas debido a las definiciones presupuestas de los términos que en ella se emplean.

Tales enunciados, no obstante, pueden expresar al menos otro tipo de significado: una proposición calificativa, clasificatoria o subsuntiva.

Si se entiende que expresa una proposición analítica, el enunciado

«Los contratos celebrados los domingos son contratos sacrílegos»

no versa, por definición, sobre el mundo, sino que constituye simplemente el resultado de la aplicación de reglas semánticas presupuestas, constatadas o estipuladas.

En cambio, si se entiende como enunciado que expresa una proposición calificativa de una clase de individuos mediante un cierto predicado, el enunciado «Los contratos celebrados los domingos son contratos sacrílegos» es un enunciado sintético: en el sentido que sirve para decir, o hacer, algo en un mundo posible. Y será, según los contextos (y los puntos de vista):empíricamente verdadero o falso, jurídicamente correcto o incorrecto, legalmente fundado o infundado, etc. Nótese que, entendidos estos enunciados de este modo, se diluye la distinción cualitativa trazada por Alchourrón y Bulygin entre «subsunción individual» y «subsunción genérica $\gg{ }^{11}$.Entre los dos tipos de subsunción sólo persiste una diferencia cuantitativa, ya que en ambos casos el enunciado subsuntivo expresa una proposición sintética. Se puede distinguir, por tanto, entre dos tipos de«subsunción genérica»: un primer tipo, tomado en consideración por Alchourrón y Bulygin, consiste en subsumir un predicado en otro predicado, más amplio que el primero, sobre la base de reglas semánticas preconstituidas y presupuestas; un segundo tipo de subsunción consiste, en cambio, en subsumir un conjunto dado de individuos en un predicado, sobre la base de reglas semánticas

${ }^{10}$ Cfr. J. Hospers, An Introduction to Philosophical Analysis, Englewood Cliffs, N.J., Pentice-Hall, II ed., 1967, pp. 160-169.

${ }^{11}$ C.E. Alchourrón y E. Bulygin, «Los límites de la lógica y el razonamiento jurídico», cit., pp. 304-309. 
preconstituidas y presupuestas, y de pertinentes investigaciones empíricas.

Cuando los jueces, a la hora de motivar una sentencia, utilizan un enunciado del tipo «Los contratos celebrados los domingos son contratos sacrílegos», ¿simplemente están formulando una verdad analítica o, al menos en algunos casos, es presumible que estén haciendo, y diciendo, alguna otra cosa? Cuando, en sede de reconstrucción silogística del contenido de una sentencia, se introduce entre las premisas y las conclusiones de un silogismo un enunciado de este tipo, ¿tal enunciado expresa necesariamente una verdad analítica o puede también asumir un significado distinto, no analítico sino sintético? Estas preguntas sirven de introducción a ulteriores consideraciones.

\subsubsection{Enunciados interpretativos «analíticos» y justificación de las decisiones judiciales}

Según Alchourrón y Bulygin, en algunos casos la verdad de los enunciados interpretativos analíticos se fundamenta en enunciados descriptivos. Dado el enunciado metalingüístico según el cual «En el uso ordinario, la locución "contratos sacrílegos" denota (también) los contratos celebrados en domingo», sería analíticamente verdadero, por razones semánticas, el enunciado «Los contratos celebrados en domingo son sacrílegos».

Esto sin duda es correcto. Sin embargo, es dudoso que una conclusión como ésta tenga relevancia para la justificación de las decisiones judiciales. Así, una decisión puede llamarse justificada si se satisfacen al menos las siguientes condiciones: a) que el contenido de la decisión sea configurable como la conclusión de una inferencia a partir de una premisa mayor normativa y de una premisa menor factual (condición expresamente indicada por Alchourrón y Bulygin); b) que cada una de las premisas utilizadas sea a su vez configurable: o como la conclusión de una inferencia, o como una aserción analíticamente verdadera ala vista de una definición (lexicográfica o estipulativa) jurídicamente justificada. Se sigue de ello que una constatación lexicográfica (y de forma más precisa: una definición lexicográfica parcial), aisladamente considerada, no puede justificar lógica y jurídicamente la aserción según la cual «Los contratos celebrados en domingo son sacrílegos», a menos que se introduzca, o se explicite, una premisa ulterior a partir de la cual sea posible construir un razonamiento deductivo. Es preciso introducir, por ejemplo, una premisa del tipo: «Debe entenderse que los signos descriptivos usados por el legislador en las disposiciones denotan lo que ellos denotan en el lenguaje ordinario». De tal premisa normativa, y de la ulterior premisa, factual, según la cual «El signo descriptivo "contrato sacrílego", usado por el legislador en la disposición D, en el uso ordinario denota 
también los contratos celebrados en domingo», se sigue lógicamente la conclusión: «Debe entenderse que el signo descriptivo «contratos sacrílegos», usado por el legislador en la disposición $\mathrm{D}$, denota también los contratos celebrados en domingo». Sobre la base de tal razonamiento deductivo, el enunciado «Los contratos celebrados en domingo son sacrílegos» aparece no sólo como analíticamente verdadero (si se quiere entender como enunciado analítico), sino también jurídicamente justificado (aunque sea de un modo indirecto).

Ello muestra que es preciso distinguir la verdad del enunciado analítico de su justificación en el ámbito del discurso jurídico. La verdad del enunciado puede depender simplemente de una constatación lexicográfica. Su (indirecta) justificación lógica y jurídica, sin embargo, requiere que se introduzcan -y se seleccionen e individualicen previamente- ulteriores premisas, Desde un punto de vista lógico, en efecto, el enunciado interpretativo analítico no es configurable como el resultado de una inferencia a partir del enunciado constatativo. Desde un punto de vista jurídico, una simple constatación no es idónea para justificar nada, ya que, como sugieren los propios Alchourrón y Bulygin, la justificación jurídica debe fundamentarse también en alguna premisa normativa.

Nótese que, asumiendo que nos hallamos ante un sistema jurídico de tipo europeo continental, la premisa mayor del silogismo es un enunciado que expresa un precepto interpretativo derivado: específicamente, el precepto según el cual se debe atribuir a los signos descriptivos usados por el legislador la misma denotación que tienen -tal como es constatableen el uso ordinario. La premisa menor es un enunciado factual. La conclusión es un enunciado que expresa una regla interpretativa, que tiene que ver con la interpretación-producto de una determinada disposición legislativa (que contenga la locución «contratos sacrílegos»), cuyo contenido es el resultado de una inferencia a partir del precepto derivado y de la premisa factual.

Las mismas consideraciones valen para la tesis de que, en algunos casos, la verdad de los enunciados interpretativos analíticos se fundamenta en enunciados metalingüísticos estipulativos. Dado el enunciado metalingüístico «Por estipulación, el signo descriptivo "contratos sacrílegos" denota también los contratos celebrados en domingo», sería analíticamente verdadero, por razones semánticas, el enunciado «Los contratos celebrados en domingo son sacrílegos».

Esto es sin duda correcto. Sin embargo, es dudoso que una conclusión como ésta tenga relevancia para la justificación de las decisiones judiciales. En efecto, ¿cómo es posible que una estipulación lexicográfica, aisladamente considerada, pueda justificar lógica y jurídicamente la aserción «Los contratos celebrados en domingo son sacrílegos»? No puede hacerlo, salvo 
que se introduzca, o se explicite, una ulterior premisa sobre la cual sea posible construir un razonamiento deductivo. Por ejemplo, una premisa del tipo: «Deben entenderse que los signos descriptivos utilizados por el legislador en las disposiciones denotan lo que ellos denotan según la (prudente) estipulación de los órganos de aplicación». De tal premisa normativa, y de la ulterior premisa, estipulativa, según la cual «Por (prudente) estipulación, el signo descriptivo "contrato sacrílego" usado por el legislador en el uso ordinario denota también los contratos celebrados en domingo» se sigue lógicamente la conclusión: «Debe entenderse que el signo descriptivo "contratos sacrílegos", usado por el legislador, denota también los contratos celebrados en domingo». También en este caso el razonamiento que justifica, indirectamente, el enunciado analítico está formado por un silogismo, cuya premisa mayor es un enunciado que expresa un precepto interpretativo derivado; cuya premisa menor es un enunciado que expresa una estipulación; y cuya conclusión es un enunciado regulativo de la interpretación-producto de una determinada disposición (que contiene la locución «contratos sacrílegos»).

Teniendo en cuenta las anteriores consideraciones, es dudoso que un juez, para justificar una decisión, pueda limitarse a usar enunciados interpretativos analíticos. Estos enunciados deben a su vez estar justificados, y la justificación, desde un punto de vista lógico y jurídico, sólo pueden ofrecerla enunciados interpretativos constatativos o estipulativos (o «decisorios»), unidos a enunciados que expresen preceptos interpretativos derivados.

\section{La estructura silogística del razonamiento judicial}

En la cultura jurídica (occidental) moderna, los estudiosos que se han ocupado de la aplicación judicial del derecho suelen utilizar con cierta frecuencia expresiones tales como: «silogismo», «silogismo práctico», «silogismo jurídico», «silogismo judicial», «silogismos judiciales», y similares. Buena parte de los discursos sobre el tema, además, afronta problemas del siguiente tipo: si la aplicación judicial del derecho consiste (o no) en un silogismo; si la sentencia es (o no) un silogismo; si el juez llega a la decisión mediante un silogismo, o no, etc. $\mathrm{Al}$ respecto, es oportuno distinguir al menos cinco tipos de discurso:

1) teorías silogísticas del razonamiento decisorio;

2) doctrinas silogísticas del razonamiento decisorio;

3) teorías silogísticas del razonamiento justificatorio;

4) doctrinas silogísticas del razonamiento justificatorio;

5) metodologías silogísticas de análisis de las sentencias.

1) Teorías silogísticas del razonamiento decisorio. Según estas teorías, el razonamiento decisorio (o razonamiento in mente judicis), a través del 
cual el juez llega a la decisión de la controversia, es de hecho un razonamiento silogístico: el juez, basándose en una actividad puramente cognoscitiva, comprueba la norma aplicable al caso (premisa mayor) y el hecho (premisa menor). Una vez hecho lo anterior, el contenido de la decisión adoptada en la sentencia se seguiría lógicamente de las dos premisas. Este modo de ver las cosas, puede atribuirse, por ejemplo, al jurista italiano Alfredo Rocco (1875-1935) ${ }^{12}$ :

«La operación a través de la cual, dada una norma general, se determina cuál es la conducta que debe seguir en el caso concreto el individuo sujeto a la norma, es una pura operación lógica; es -como suele decirse- un silogismo, en el que una vez asumida como premisa mayor la norma general, como menor el hecho concreto, se deduce la norma de conducta que debe seguirse en el caso individual».

Las teorías silogísticas del razonamiento decisorio hace tiempo que están desacreditadas, al menos a los ojos de los juristas más avezados, que las consideran, según los casos: teorías falsas -o, al menos, excesivamente simples- de la aplicación judicial del derecho; o ideologías camufladas de los discursos prescriptivos, presentadas como fieles descripciones de fenómenos de aplicación, pero que en realidad pretenden dar crédito al mito del juez mecánico aplicador de la ley e inmune a la responsabilidad moral o política ${ }^{13}$.

2) Doctrinas silogísticas del razonamiento decisorio. La tesis central de este tipo de discursos, de naturaleza prescriptiva, puede resumirse así: el razonamiento decisorio de los jueces debe consistir, en la medida de lo posible, en un razonamiento de tipo silogístico. Se trata de un objetivo ideal, no completamente realizable, cuyo seguimiento concienzudo puede dar resultados apreciables para quien se adhiera a la implícita ideología jurídica liberal. En efecto, tales doctrinas requieren: a) que, en la medida de lo posible, las leyes estén formuladas de manera cuidadosa, con claridad y precisión; b) que, en la medida de lo posible, se trace una clara línea de demarcación entre lo que está regulado y lo que es jurídicamente irrelevante; c) que la interpretación judicial sea, en la medida de lo posible, literal. El más ilustre representante de esta doctrina del razonamiento judicial -en relación al derecho y al proceso penal- ha sido Cesare Beccaria, el cual, en un famosísimo pasaje de Del delitti e delle pene (1764, ed. 1766), afirma: «En todo delito debe establecer el juez un silogismo perfecto: la premisa mayor corresponde a la ley general, la menor a la acción conforme o no con la ley, la conclusión a la libertad o a la pena. Cuando el juez, por fuerza o por

\footnotetext{
${ }^{12}$ A. Rocco, La sentenza civile. Studi, Torino, Bocca, 1906, p. 34.

${ }^{13}$ Cfr. últimamente T. Mazzarese, Forme di razionalità delle decisioni giudiziali, Torino, Giappichelli, 1996, cap.
} 1. 
voluntad, quiere efectuar más de un silogismo, abre las puertas a la incertidumbre».

3-4) Teorías y doctrinas silogísticas del razonamiento justificatorio. Un rasgo común a estos tipos de discurso es la idea de que hay que entender el razonamiento judicial formulado en las sentencias no como la exteriorización del razonamiento decisorio, sino como un razonamiento justificatorio: como el conjunto de las razones jurídicas en favor de una decisión que podría haber sido tomada perfectamente por otras «reales» razones. Con este presupuesto, las teorías silogísticas del razonamiento justificatorio sostienen que el razonamiento formulado por los jueces en las sentencias debe ser un razonamiento deductivo silogístico: esto constituiría, en efecto, uno de los requisitos para cumplir correctamente la obligación de motivar las decisiones judiciales.

5) Metodologías silogísticas de análisis de las sentencias. Este último tipo de discursos combina contenidos teóricos con contenidos de metodología prescriptiva.

Desde el punto de vista teórico, las metodologías silogísticas no sostienen que el razonamiento decisorio o el razonamiento justificatorio sean, de hecho, razonamientos de tipo silogístico. Se limitan, más bien, a sostener las siguientes tesis, bastante más cautas:

a) el contenido de las sentencias, al menos en ciertos casos, puede ser reconstruido como un razonamiento de tipo silogístico (cfr. ap. 1.);

b) tal reconstrucción, normalmente, se compone no ya de un silogismo, sino de un conjunto de silogismos -un complejo de «numerosos silogismos concatenados» (Calamandrei); un «sorites» (Taruffo); «una cadena de silogismos» (Comanducci) ${ }^{14}$;

c) las actividades documentales de las sentencias no tienen carácter exclusivamente lógico-cognoscitivo, ni la aplicación judicial del derecho es perfectamente reducible a la formulación de un razonamiento silogístico, ya que: en primer lugar, las premisas del razonamiento judicial no son un dato de hecho que el juez se limita a constatar; en segundo lugar, y consecuentemente, la formulación de las premisas y de las conclusiones es bastante a menudo, si no siempre, fruto de opciones de diverso tipo por parte de los jueces.

\footnotetext{
${ }^{14}$ Cfr., por ejemplo, J. Wróblewski, «Legal Syllogisni and Rationality of Judicial Decision», Rechtstheorie, 5, 1974, pp. 34-46; L. Ferrajoli, Diritto e ragione. Teoria del garantismo penale, Bari, Laterza, 1989, pp. 38-41 (en relación a las sentencias penales); E. Bulygin, «Ort Legal Interpretation», cit.; P. Comanducci, Assagi di metaetica, Torino, Giappichello, 1992, cap. 3; J. Wróblewski, The Judicial Application of Law, cit., cap. IX. Cfr., además, P. Calamandrei, «La genesi logica della sentenza civile», Rivista critica di scienze sociali, 1914, p. 258; M. Taruffo, «Il giudice e lo storico: considerazioni metodologiche», Rivista di diritto processuale, 1967.
} 
Desde el punto de vista prescriptivo, las metodologías silogísticas de análisis de las sentencias se caracterizan por la idea de que la reconstrucción silogística del contenido de las sentencias es algo útil, en cuanto permite a los intérpretes captar con claridad:

a) cuáles son las premisas, explícitas o implícitas, de las decisiones judiciales;

b) si las conclusiones -o sea, las resoluciones concretamente adoptadas- se siguen lógicamente de tales premisas;

c) si la motivación explícita presenta o no saltos lógicos -sintomáticos en algunos casos de la utilización de premisas implícitas o de verdaderos vicios de la sentencia;

d) qué argumentos se han adoptado para sostener cada una de las premisas.

El método de la reconstrucción silogística constituiría, por tanto, un instrumento valioso a disposición de los intérpretes de las sentencias, ya que les permitiría examinar y valorar las decisiones jurisdiccionales, bajo el perfil del carácter completo de los argumentos y de la coherencia lógica de sus motivaciones. A la hora de diferenciar distintos tipos de silogismos judiciales y de mostrar las relaciones que pueden darse entre ellos adoptaré, como previsible, esta última cautela prospectiva.

Teniendo en cuenta los contenidos usuales de las sentencias civiles de los jueces italianos, es posible distinguir al menos cinco distintos tipos de silogismo judicial:

1) silogismos normativos;

2) silogismos interpretativos;

3) silogismos calificativos, o de subsunción;

4) silogismos de enlace;

5) silogismos probatorios.

Seguidamente ilustraré brevemente en qué consisten los tres primeros tipos de silogismos judiciales ${ }^{15}$. Dos precisiones. En primer lugar, llamo a estos silogismos «silogismos judiciales» no ya porque se trate de silogismos de hecho construidos y usados por los jueces en las sentencias, sino en cuanto son silogismos útiles para reconstruir de manera lógico-deductiva partes del contenido de las sentencias. En segundo lugar, la presente clasificación de los silogismos judiciales es sólo una clasificación entre las muchas posibles, sin pretensiones de exhaustividad. Las clases de silogismos, sin embargo, se han construido de tal forma que sean mutuamente excluyentes:

\footnotetext{
${ }^{15}$ Sobre silogismos «de enlace» y sobre silogismos «probatorios», c fr. P. Chiassoni, Il diritto giurisprudenziale. L. Casi per l'analisi delle sentenze civili, cap. 3, Milano, Giuffrè, de próxima publicación.
} 
un silogismo no puede pertenecer al mismo tiempo a más de una clase -no puede ser, por ejemplo, a la vez normativo e interpretativo.

\section{1. Silogismos normativos}

Por «silogismo normativo» entiendo, genéricamente, todo aquel silogismo judicial que, desde un punto de vista lógico: a) pertenezca a la cadena de silogismos cuya conclusión es la llamada conclusión jurídica o decisión: usualmente, la norma individual del caso; b) no sea un silogismo interpretativo, ni un silogismo de enlace.

En el ámbito de los silogismos normativos es preciso distinguir entre el silogismo de primer grado, o «silogismo decisional», por un lado, y los silogismos normativos de grado superior -de segundo, de tercer, de enésimo grado-, por otro ${ }^{16}$.

El silogismo normativo de primer grado, o silogismo decisional, es un silogismo en el que:

1) la premisa mayor es (un enunciado que expresa) la norma jurídica, general y abstracta, en base a la cual el juez considera que la controversia (puede y) debe decidirse;

2) la premisa menor es (un enunciado que expresa) una calificación, que subsume el hecho concreto en la citada norma general: en la clase de individuos a los que la norma conecta una consecuencia jurídicamente relevante;

3) la conclusión, por último, es (un enunciado que expresa) la norma jurídica, individual y concreta, que resuelve la controversia particular (o una particular cuestión o pregunta, entre las distintas sometidas al conocimiento del juez).

El silogismo normativo de segundo grado es un silogismo en el que:

1) la premisa mayor es (un enunciado que expresa) una norma jurídica más general y/o más abstracta que la de la premisa mayor del silogismo de primer grado;

2) la premisa menor es (un enunciado que expresa) una calificación, que subsume una clase de hechos concretos en la más amplia clase contemplada por la norma que constituye la premisa mayor;

3) la conclusión, por último, es (un enunciado que expresa) una norma jurídica, general y abstracta, que coincide con la premisa mayor del silogismo normativo de primer grado. Y así sucesivamente para los silogismos normativos de grado superior.

${ }^{16}$ Uso «silogismo decisional» para denotar un esquema deductivo distinto al homónimo esquema -simple o complejo- del que habla J. Wróblewski, The Judicial Application of Law, cit., pp. 198 y ss. 
Considérese, por ejemplo, la siguiente secuencia de tres silogismos normativos.

Silogismo normativo de tercer grado

Los contratos contrarios a normas imperativas son nulos (premisa normativa extraída del art. 1418 del cod. civ.)

Los contratos sacrílegos son contratos contrarios a normas imperativas

Los contratos sacrílegos son nulos.

Silogismo normativo de segundo grado

Los contratos sacrílegos son nulos.

Los contratos celebrados en domingo son contratos sacrílegos.

Los contratos celebrados en domingo son nulos.

Silogismo normativo de primer grado (silogismo decisional)

Los contratos celebrados en domingo son nulos.

El contrato entre Dulcinea Neri y Astianatte Bianchi es un contrato celebrado en domingo.

El contrato entre Dulcinea Neri y Astianatte Bianchi es nulo.

\subsection{Silogismos interpretativos}

Por «silogismo interpretativo» entiendo todo aquel silogismo cuya conclusión sea un enunciado interpretativo. Como dije antes (ap. 2), dentro de las sentencias se pueden distinguir distintos tipos de enunciados interpretativos. Por ejemplo:

1) enunciados que expresan reglas interpretativas («Las leyes deben interpretarse de forma literal»; «El art. 1418, 1, c.c. debe interpretarse de forma restrictiva», etc.) (ap. 2A., nn. 1 у 2$)$;

2) enunciados que expresan constataciones de prácticas interpretativas («La Corte de casación, en las sentencias.... ha interpretado el art. 1418. 1, c.c. de forma restrictiva»; "La doctrina interpreta el art. 1418. 1, c.c. como expresión de un principio general del derecho», etc.) (ap. 2.4., n. 11);

3) enunciados que expresan constataciones de resultados interpretativos («Para el juez Tizio un ruido constituye intromisión de carácter tolerable» si no es audible con las ventanas cerradas»; «Para la Corte de Casación, en las sentencias.... no constituye «caso fortuito» el hurto de la cosa del vehículo que el conductor haya dejado sin vigilancia»; etc.) (ap. 2.4., n. 12);

4) enunciados que expresan juicios prudenciales acerca de prácticas interpretativas («Es oportuno privilegiar en todo caso la interpretación de adecuación»; «Es conforme a derecho interpretar «caso fortuito» de forma restrictiva»; ete) (ap. 2A., n. 5); 
5)enunciados que expresan juicios prudenciales acerca de resultados interpretativos («Es absurdo que por «daño injusto» se entienda cualquier lesión en el patrimonio personal»; «Es acorde al sistema excluir de los «actos de competencia desleal» la publicidad comparativa»; etc.) (ap. 2A., n. 6);

6) enunciados que expresan el contenido de decisiones interpretativas ( A los fines de la presente decisión, constituye "daño injusto" cualquier lesión en el patrimonio personal»; «A los fines de la presente decisión, "sentencia" designa cualquier resolución judicial de carácter decisorio»; etc.) (ap. 2A., nn. 13 y 14).

Se pueden reconstruir, consecuentemente, diversos tipos de silogismo interpretativo, según el tipo de enunciado interpretativo que constituya la conclusión. A continuación, en vez de caer en una (forzosamente) pesada tipología de los silogismos interpretativos, me limitaré a ejemplificar la reconstrucción silogística de un razonamiento interpretativo judicial. Se trata del razonamiento mediante el cual la Corte de Casación italiana, en la sentencia n. 10959/1996,justifica una interpretación (presentada como) extensiva de la locución «incorporaciones no separables» contenida en el art. 1593 del código civil ${ }^{17}$.

Brevemente, los hechos de la causa. En 1938, un local de uso comercial situado en la plaza Carlo Felice, en el centro de Turín, se había concedido en arrendamiento al titular del Bar-Confitería Talmone. Este último incorporó al inmueble elementos decorativos de gran valor artístico ya utilizados en un local anterior del siglo XIX, «para singularizar la nueva confitería». Los elementos decorativos permanecieron en el local a pesar de los sucesivos cambios de propiedad, transformándose cada vez en propiedad de los nuevos titulares. En la segunda mitad de los años setenta, el ministro de cultura declaró «de interés particularmente importante, en el sentido del art. 2 de la ley n. 1089/1939, la Confitería Roma, ya Talmone, su actual destinación de uso conjuntamente con la decoración, que constituye su imprescindible presupuesto».La resolución, impugnada en vía administrativa, fue confirmada y se convirtió en definitiva. En el mismo período de tiempo, el propietario de los locales, la sociedad Inmobiliaria Santa Costanza, obtenía la ejecución de desalojo por morosidad frente al arrendatario, Sra. Chiesa, la cual en el intervalo que duró el procedimiento de desalojo,

${ }^{17}$ Art. 1592. Mejoras.- «(...) el arrendatario no tiene derecho a ser indemnizado por las mejoras aportadas a la cosa arrendada. Pero si ha habido consentimiento del arrendador, éste debe pagar una indemnización correspondiente a la menor suma entre el importe del gasto y el valor del resultado útil en el momento de la devolución (...)».

Art. 1593. incorporaciones.- «El arrendatario que ha aportado las incorporaciones sobre la cosa arrendada tiene derecho a quitarlas al final del arrendamiento siempre que esto pueda suceder sin menoscabo de la cosa, salvo que el propietario prefiera conservar las incorporaciones. En tal caso, éste debe pagar al arrendatario una indemnización igual a la menor suma entre el importe del gasto y el valor de las incorporaciones en el momento de la devolución.

Si las incorporaciones no son separables sin menoscabo de la cosa y constituyen una mejora, se observarán las normas del artículo anterior». 
traspasó el establecimiento a terceros. Después de estos acontecimientos la situación quedó como sigue: 1) los nuevos titulares del establecimiento -Srs. Fina y Condarcuri- se encontraron bajo la condición de propietarios de los elementos decorativos ya mencionados que, según lo dispuesto por la autoridad administrativa, no podían ser separados, pues ya no existía disponibilidad en este punto; 2) la sociedad Santa Costanza se encontraba en la condición de propietario de un inmueble ahora ya libre de personas pero en el cual, por decisión administrativa, debían permanecer aquellos elementos decorativos propiedad de terceros (específicamente: los últimos adquirentes del Bar-Confitería Talmone). Cada una de las partes solicitó a la autoridad judicial que impusiera a la otra una solución que reuniera en un mismo sujeto la titularidad del inmueble y de la decoración a él vinculada. En primera instancia, el tribunal de Turín, basándose en una interpretación extensiva del art. 1593 del código civil, atribuyó la titularidad de la decoración al propietario del inmueble. La sentencia, sin embargo, fue revocada por el tribunal de apelación, el cual estableció que la titularidad de los inmuebles y de la decoración debía permanecer separada. Esta última sentencia fue impugnada después ante la Corte suprema de casación, que la anuló en base a las consideraciones que a continuación se transcriben.

Corte de Casación, sección III, 9 diciembre 1996, n. 10959

«La sentencia (del tribunal de apelación de Turín) resulta (...) censurable cuando sostiene que el conflicto de intereses de que se trata no estaba regulado en ninguna norma y no podía ser definido a menos que se estableciera la permanencia de los respectivos originarios títulos de propiedad separada sobre los bienes unidos por el vínculo administrativo.

Debe entenderse como fundado el motivo de recurso principal que asume la atribución de los bienes muebles, transformados en inseparables del inmueble arrendado en función del vínculo impuesto al propietario del inmueble, en base a las reglas generales que regulan tales situaciones con referencia a las relaciones entre arrendador y arrendatario, solución ya asumida con suficiente motivación por el tribunal de Turín, que ha justamente equiparado la inescindibilidad jurídica a la más frecuente inescindibilidad de hecho.

La tesis del tribunal de Turín según la cual la normativa no sería aplicable, pensando que la normativa de los arts. 1592 y 1593 c.c. establece una regulación distinta en función de la obligación o no del propietario de pagar indemnización por los bienes así adquiridos, resulta infundada. (...)

Militan más razones en favor de la solución sobre la aplicabilidad de la regla establecida en los citados artículos 1592 y 1593 c.c. a los casos de incorporaciones llevadas a cabo por el arrendatario, y ya inseparables, no debido a las características físicas, sino por vínculo jurídico.

Es una regla general del ordenamiento, en las diversas situaciones en las que se da una mezcla entre bienes muebles e inmuebles, la de expandir la propiedad inmobiliaria a los bienes muebles que sean inamovibles. Nótese, al respecto, que la inamovibilidad no es nunca una realidad absoluta, sino que surge en muchas ocasiones de una valoración económica.

El hecho de que exista una distinta titularidad sobre bienes inseparables, cuando no se configura la creación de (una) comunión de derechos sobre la nueva entidad así formada, resulta una hipótesis extraña al sistema, en cuanto es por 
sí misma idónea para generar conflictos de intereses e imposibilidad en la gestión del bien.

Es un principio jurídico asumido que la indivisibilidad de un bien puede depender tanto de su naturaleza como de su destino, aunque sean razones de interés público las que excluyan la división en cada uno de sus componentes. Al respecto, recuérdese, por ejemplo, que el art. 1316 c.c. confirma que el concepto de divisibilidad tiene naturaleza esencialmente jurídica, si bien no prescinde de la estructura del bien tomado en consideración. La norma citada establece, en efecto, que una cosa -o un hacer- no son susceptibles de división, ya sea por su naturaleza o por el modo en que ellos han sido considerados por las partes contratantes ${ }^{18}$.

La equiparación entre indivisibilidad jurídica e indivisibilidad material resulta ser, por tanto, (un) dato normativo, recogido en el ordenamiento.

Así, pues, la indivisibilidad entre bienes puede legítimamente hacerse proceder de lo dispuesto en la ley o de un vínculo administrativo; la obligación del arrendatario o del que detenta el inmueble en su integridad comprende necesariamente las incorporaciones producidas en el curso de la utilización de la cosa arrendada, y que ya no son separables.

En 1938 el gestor de la confitería Talmone, arrendando el inmueble de la plaza Carlo Fenice, en su intento de reconstruir el ambiente del siglo XIX, utilizó decoración de la época.

Según el juicio de la Administración pública, aún si es falso históricamente, el ambiente creado evocaba la atmósfera del risorgimento turinés, y por tanto el conjunto así formado debía entenderse que representaba una unidad inescindible y tutelable.

La imposición del vínculo, pues, ha tenido como efecto la indivisibilidad de las pertenencias -constituidas por la decoración- respecto al inmueble en el que dicha ambientación se había realizado. Una correcta interpretación, aunque extensiva, de los arts. 1592 y 1593 c.c. permite de este modo afirmar que el propietario del inmueble tiene título para adquirir las incorporaciones realizadas, si acaso con su consentimiento, y jurídicamente indivisibles.

(...) En conclusión, por tanto, aceptando el recurso principal, debe anularse la sentencia impugnada y debe establecerse el reenvío de los autos a otra sección del tribunal de apelación de Turín, el cual, según lo dispuesto en el art. 384 c.p.c., observará el siguiente principio de derecho:

"Son aplicables las normas de los arts. 1592 y 1593 del código civil, también al caso en que las (incorporaciones) realizadas por el arrendatario, que aun siendo por su naturaleza física separables, hayan pasado a ser jurídicamente inseparables, bien sea por una disposición legislativa o por un vínculo administrativo (...)"»».

Desde la perspectiva de la metodología silogística de análisis de las sentencias, el razonamiento interpretativo de la Corte de casación puede ser reconstruido mediante al menos tres distintos silogismos interpretativos.

${ }^{18}$ Art. 1316. Obligaciones indivisibles- «La obligación es indivisible, cuando la prestación tiene por objeto una cosa o un hecho que no es susceptible de división por su naturaleza o por el modo en que ha sido considerado por las partes contratantes». 


\section{Primer silogismo interpretativo}

Si la solución del caso «Confitería Talmone», sobre la única base de las disposiciones legislativas entendidas de forma literal y sin recurrir a la interpretación extensiva o a la analogía, conduce a resultados «extraños al sistema», entonces el caso "Confitería Talmone» debe decidirse procediendo a la interpretación extensiva o a la analogía (premisa ex art. 12.2. disp. prel. c.c.).

La solución del caso «Confitería Talmone», sobre la única base de las disposiciones legislativas entendidas de forma literal y sin recurrir a la interpretación extensiva o a la analogía, conduce a resultados «extraños al sistema», (al «permanecer distinta titularidad sobre bienes inseparables»).

El caso «Confitería Talmone» debe decidirse acudiendo a una interpretación extensiva o a la analogía.

Segundo silogismo interpretativo

$\mathrm{Si}$, a la luz del «ordenamiento», las situaciones de indivisibilidad jurídica y de indivisibilidad material entre bienes inmuebles y bienes muebles resultan equiparadas, entonces las incorporaciones inseparables por vínculo administrativo pueden «legítimamente» considerarse similares a las incorporaciones inseparables por razones materiales.

A la luz del «ordenamiento» (cfr. art. 1316 c.c. y el relativo «principio jurídico» implícito), las situaciones de indivisibilidad jurídica y de indivisibilidad material entre bienes inmuebles y bienes muebles resultan equiparadas.

Las incorporaciones inseparables por vínculo administrativo pueden «legítimamente» considerarse similares a las incorporaciones inseparables por razones materiales.

Tercer silogismo interpretativo

Si las incorporaciones inseparables por vínculo administrativo pueden «legítimamente» considerarse similares a las incorporaciones inseparables por razones materiales, entonces los arts. 1592 y 1593 c.c. deben interpretarse extensivamente, de tal modo que regulen también las incorporaciones inseparables por vínculo administrativo.

Las incorporaciones inseparables por vínculo administrativo pueden «legítimamente» considerarse similares a las incorporaciones inseparables por razones materiales.

Los arts. 1592 y 1593 c.c. deben interpretarse extensivamente, de tal modo que regulen también las incorporaciones inseparables por vínculo administrativo. 
Observaciones.

1) El primer silogismo interpretativo tiene como conclusión el precepto individual, según el cual, para decidir el caso «Confitería Talmone» se debe recurrir a los instrumentos indicados en el art. 12.2. disp. prel. c.c. ${ }^{19}$. Tal conclusión, en el particular contexto en el que se encuentra la decisión de la Corte, no era nada pacífica. En efecto, según el Tribunal de apelación de Turín, el caso debiera haber sido regulado de otro modo, sin que existiera, en opinión de este Tribunal, ninguna laguna que legitimase el recurso a la interpretación extensiva o analógica. Para la Corte de Casación, en cambio, como se aprecia en este silogismo, la laguna existe: la solución dada por el tribunal de apelación, lejos de ser la única conforme a derecho, resulta ser «extraña al sistema». La laguna que la Corte Suprema -compartiendo la opinión del juez de primera instancia- considera que subsiste y debe ser colmada es, si nos fijamos bien, una laguna axiológica (según la conocida taxonomía de Alchourrón y Bulygin): podría también hallarse una solución jurídica sin recurrir al razonamiento analógico, pero se trataría de una solución incompatible son el «sistema» («extraña al sistema»), tal como es reconstruido por la propia Corte.

2) El tercer silogismo interpretativo tiene como conclusión un precepto interpretativo derivado que coincide, grosso modo, con el principio de derecho formulado por la Corte al final de la motivación, de acuerdo con el art. 384.1, c.p.c.

3) Las conclusiones del primer y tercer silogismo son prescripciones interpretativas: se podría, por tanto, hablar de silogismos interpretativos «regulativos», para después realizar distinciones entre ellos a la vista de los distintos tipos de preceptos interpretativos -preceptos no derivados, preceptos derivados, preceptos meramente reiterados, preceptos no meramente reiterativos, preceptos deducidos de un precepto derivado y de una premisa factual, etc.

4) El segundo silogismo, a diferencia de los otros dos, no es «regulativo», sino «estimativo». La conclusión esta formada, no ya por una prescripción interpretativa, sino por un juicio acerca de la similitud relevante entre las incorporaciones inseparables de un inmueble por razones jurídicas (concretamente, debido a un vínculo administrativo), por una parte, y las incorporaciones inseparables de un inmueble por razones materiales (de acuerdo a la «naturaleza del bien»), por otra. El juicio acerca de la similitud relevante de dos casos -uno de ellos explícitamente regulado por el derecho-

${ }^{19}$ Art. 12.2, disp. prel. cod. civ.: «Si una controversia no puede decidirse con una determinada disposición, se tendrán en cuenta las disposiciones que regulan casos, similares o materias análogas; si el caso sigue siendo dudoso, se decidirá según los principios generales del ordenamiento jurídico del Estado». 
es un componente esencial de todo argumento tendente a acreditar la interpretación extensiva de un enunciado legislativo o la aplicación analógica de una norma. La reconstrucción silogística pone de relieve esta relación. Así, el segundo y el tercer silogismo aparecen concatenados: la conclusión del segundo silogismo es idéntica al antecedente de la premisa mayor y a la premisa menor del tercer silogismo. Además, a la luz del segundo silogismo, el carácter apodíctico de la premisa menor del tercer silogismo desaparece, encontrando en aquél su justificación.

5) Por el contrario, no hay conexión lógica entre el primer silogismo interpretativo, por un lado, y los otros dos silogismos, por otro. Este hecho podría depender de la presente reconstrucción. En todo caso, es preciso mostrar que: entre los tres silogismos subsiste al menos una conexión justificatoria, o argumentativa. Así, el primer silogismo reconstruye la justificación adoptada por la Corte en favor de la decisión de censurar la solución propuesta por el tribunal de apelación y de imponer, en consecuencia, al juez de reenvío el principio de derecho acreditado de las maneras reconstruidas por el segundo y el tercer silogismo.

6) Se podría entender el segundo silogismo como justificación de la tesis interpretativa según la cual «incorporaciones no separables» denota tanto las incorporaciones materialmente inseparables, como las jurídicamente inseparables. A la vista de todo ello, y adoptando la perspectiva de Alchourrón y Bulygin, se podría formular el enunciado interpretativo analítico: «Las incorporaciones jurídicamente inseparables son incorporaciones no separables». Un enunciado de este tipo, empero, no sería el único enunciado interpretativo usado con fines justificatorios; ni sería el más relevante desde el punto de vista del cumplimiento de la obligación de motivar.

\subsection{Silogismos calificativos}

Por «silogismo calificativo» entiendo, genéricamente, todo silogismo cuya conclusión sea un enunciado calificativo o clasificatorio o subsuntivo.

Los silogismos calificativos son la forma lógica de la operación intelectual conocida como subsunción. Es posible distinguir, como se ha dicho, dos tipos de subsunción: genérica e individual ${ }^{20}$. La subsunción genérica puede ser a su vez de dos tipos, como se ha visto (ap. 2.5. 1.), según que se entienda como subsunción de un predicado en otro predicado, o como subsunción de un conjunto de individuos en un predicado. De este modo, es posible distinguir, en el ámbito de los silogismos calificativos, entre silogismos genéricos y silogismos individuales. Por ejemplo:

\footnotetext{
${ }^{20}$ Sobre la subsunción, además de los trabajos de Alchourrón y Bulygin citados, cfr. G. Lazzaro, «Sussunzione», Novissimo Digesto Italiano, vol. 18, 1971, pp. 975-977 (y las referencias bibliográficas allí indicadas).
} 


\section{Silogismo calificativo genérico}

Los contratos contrarios a preceptos religiosos son contratos sacrílegos.

Los contratos celebrados en domingo son contratos contrarios a preceptos religiosos.

Los contratos celebrados en domingo son contratos sacrílegos.

Silogismo calificativo individual

Los contratos celebrados en domingo son contratos sacrílegos. domingo.

El contrato entre Astianatte Bianchi y Dulcinea Neri es un contrato celebrado en

El contrato entre Astianatte Bianchi y Dulcinea Neri es un contrato sacrílego.

Los ejemplos ponen de relieve los siguientes aspectos de los silogismos calificativos.

1) La conclusión del silogismo calificativo individual coincide con la premisa menor de un silogismo normativo de primer grado cuya premisa mayor es, por ejemplo, la regla jurídica: «Los contratos sacrílegos son nulos» (cfr. ap. 3.1.).

2) El silogismo calificativo genérico reformula (en su estructura esencial) el razonamiento que permite subsumir el hecho concreto -el contrato celebrado en domingo entre Astianatte Bianchi y Dulcinea Neri- en la norma: «Los contratos sacrílegos son nulos». Ello sucede a través del término medio «contratos contrarios a preceptos religiosos».

3) La premisa mayor del silogismo calificativo genérico presupone un precepto interpretativo del tipo: «Por "contrato sacrílego", a los fines de la aplicación del art. X del código civil, debe entenderse todo contrato contrario a preceptos religiosos». Desde un punto de vista argumentativo, por tanto, este silogismo se encuentra coordinado con al menos un silogismo interpretativo, cuya conclusión es el citado presupuesto.

4) Aunque se considere que el enunciado «Los contratos contrarios a preceptos religiosos son contratos sacrílegos» expresa una aserción analítica, no es idóneo, por sí sólo, para justificar la conclusión del silogismo subsuntivo individual; ni mucho menos para justificar la decisión de que el contrato entre Astianatte Bianchi y Dulcinea Neri es un contrato nulo.

\subsection{Relaciones entre silogismos judiciales}

Entre los distintos tipos de silogismo judicial se dan, según los casos, los siguientes tipos de relación:

1) relaciones de concatenación lógica;

2) relaciones de coordinación argumentativa o justificativa; 
3) relaciones de coordinación praxeológica;

4) relaciones de convergencia praxeológica.

1) Concatenación lógica. Dos o más silogismos judiciales están «lógicamente concatenados» cuando tienen en común al menos un elemento relevante para la deducción. La concatenación lógica puede ser de dos tipos: concatenación «vertical» o concatenación «transversal» (u «horizontal» o «colateral»).

La concatenación entre silogismos es «vertical» cuando, por ejemplo, la conclusión de un silogismo coincide con la premisa mayor de otro -como puede apreciarse en las secuencias de silogismos normativos o calificativos ejemplificados anteriormente (aps. 3.1., 3.3.) ${ }^{21}$.

En cambio, la concatenación es «transversal» cuando la conclusión de un silogismo coincide con la premisa menor de otro silogismo -como se observa en el segundo y tercer silogismo interpretativo (ap. 3.2.).

2) Coordinación argumentativa. Dos silogismos judiciales están coordinados entre ellos de forma argumentativa, cuando el primer silogismo acredita una conclusión que, por sí misma o junto con otros argumentos, participa en la justificación de la conclusión del segundo silogismo, aunque no forme parte de sus premisas, ni de la misma concatenación de silogismos. Como se ha visto, tiene lugar una coordinación de este tipo entre el primer silogismo interpretativo, que justifica el recurso a la interpretación extensiva o a la analogía en el caso «Confitería. Talmone», por un lado, y los otros dos silogismos interpretativos, que justifican la interpretación extensiva de los arts. 1592 y 1593 c.c. (ap. 3.2), por otro.

3) Coordinación praxeológica. Dos silogismos judiciales están «coordinados praxeológicamente» cuando: a) no están lógicamente concatenados: b) la cuestión resuelta de la forma indicada por un silogismo es una cuestión distinta y autónoma, desde un punto de vista lógico-jurídico o argumentativo, respecto a la cuestión sobre la que versa el otro silogismo. Están típicamente coordinados de manera praxeológica dos silogismos decisionales cuyas respectivas conclusiones constituyan la solución de distintas cuestiones planteadas en el mismo grado de juicio, entre las mismas partes. Piénsese, por ejemplo, en el silogismo decisional cuya conclusión resuelve, positivamente, una cuestión de jurisdicción (estableciendo, pongamos por caso, que «El juez civil italiano tiene jurisdicción en la controversia Schwarzkopf Travemünde A.G. c. Eleuterio Tiscornia s.a.s.») y en el silogismo decisional, reconstruible sobre la base de la misma sentencia-documento, cuya conclusión resuelve una cuestión de fondo (estableciendo, pongamos

\footnotetext{
${ }^{21}$ Otro caso de concatenación vertical -ejemplificado por los dos últimos silogismos interpretativos en ap. 3.2.se da cuando la conclusión de un silogismo coincide con el antecedente de la premisa mayor hipotética de otro silogismo.
} 
por caso, que: «Schwarzkopf Travemünde A.G. debe entregar a Eleuterio Tiscornia s.a.s. las mercancías convenidas»).

4) Convergencia praxeológica. Por último, dos o más silogismos normativos se relacionan por «convergencia praxeológica» si: a) no están lógicamente concatenados; b) sirven para resolver una misma cuestión, de maneras jurídicamente equivalentes, pero utilizando una premisa mayor distinta. Cuando el contenido de una sentencia permite la reconstrucción de uno o más silogismos normativos caracterizados por convergencia praxeológica, entonces se debe concluir que esa sentencia-documento presenta una «pluralidad de rationes decidendi», o dos o más «autónomas y concurrentes rationes decidendi»» ${ }^{22}$.

\section{Conclusiones}

Tomando como punto de partida dos tesis de Alchourrón y Bulygin, he elaborado una tipología de los enunciados interpretativos y una tipología de los silogismos judiciales, ninguna de las cuales, no está de más repetirlo, pretende ser exhaustiva, ni mucho menos excluyente.

La primera tipología querría ser una contribución metodológica, sólo en esbozo, al análisis de los discursos interpretativos, que permita captar la variedad de contenidos, frente a cualquier reduccionismo. Si en el ap. 2. he aducido argumentos en favor de una noción de «enunciado interpretativo» distinta de la usada por Alchourrón y Bulygin, lo he hecho por la propia exigencia de claridad conceptual y no para dar pie a fútiles cuestiones terminológicas.

La tipología de los silogismos judiciales responde a varios objetivos. Me limito a destacar dos, además del indicado en la «Introducción». En primer lugar, poner de relieve que, bajo ciertas condiciones, el uso de un razonamiento silogístico en el análisis del discurso judicial no implica ningún compromiso con las (hoy ya desacreditadas) teorías «mecanicistas» de la aplicación del derecho. En segundo lugar, contribuir a la elaboración de un modelo normativo de razonamiento justificatorio judicial: un modelo acerca de cómo los jueces deberían motivar las sentencias, con el fin de facilitar el control de las partes, de los jueces superiores, de los órganos legislativos y de la opinión pública sobre sus decisiones.

(Trad. J.M. Vilajosana)

${ }^{22}$ Cfr. M. Lupoi, «Pluralità di “rationes decidendi” e precedente giudiziale», en Foro italiano, Quaderni, 1967, pp. 203 ss.

DOXA 20 (1997) 